\title{
A Comparative Study of the Economic Impact of Tourism on the West African Economies
}

\author{
Fei Miriam Nana Serwa* \\ College of Tourism management, Central South University of Forestry and Technology, \\ Changsha, Hunan, China \\ miriamfei88@gmail.com \\ Fen Luo \\ College of Tourism management, Central South University of Forestry and Technology, \\ Changsha, Hunan, China \\ fen.1@csuft.edu.cn
}

\begin{abstract}
The tourism sector is an imperative source of economic growth which is a composition of both income per capita, GDP per capita, foreign exchange earnings, and employment. These factors are assumed to contribute to economic development of the west African subregion. This research is focused on investigating the comparative impact tourism industry has on economic growth and the contrariwise. In order to realize this goal, we estimated a dynamic panel using the estimator of the systems generalized method of moment's (GMM) coupled with pooled ordinary least squares (POLS) which are applied to about eight economically viable west African countries for the period 1999 - 2019. This research is an addition to the incomplete empirical studies on the effect tourism has on economic growth and the contrariwise between west African countries. Also, this research contributes by building on preceding researches by presenting a primal possible factor of economic growth, such as the observation of corruption, and by utilizing significant quadratic and collaborating effects. The results show that an increase tourism performance results in a maximum level of economic growth and the west African countries with a high supposed level of corruption have a minimal level of economic growth. By utilizing the economic growth model, we also observed a substantial positive influence of the tourism industry on economic growth of the west African countries. Likewise, the results of econometric analysis for the tourists arrival model show that economic growth is very important for the progression of the tourism industry. Hence, west African countries are encouraged to establish a very favorable environment (for instance, political stability) and invest their capitals to upsurge the influence of the tourism industry to national income and overall economic growth rate.
\end{abstract}

Keywords: Tourism, west-Africa, Tourists Arrival, Domestic tourism, Panel data, Economic growth.

DOI: $10.7176 / \mathrm{JTHS} / 56-01$

Publication date:May $31^{\text {st }} 2021$

\section{Introduction}

Tourism has over time, been among the quickest growing sectors and in fact the world's largest industry, it accounts for more than one-third of the total value of global services trade (UNWTO 2006b). Between 1950 to 2006, Global tourism phenomenally grew to above 825 million arrivals from 25 million. Which means an annual average rate of growth at 6.5 percent (UNWTO 2007). Travel and tourism's contribution to gross domestic product (GDP) was expected to grow to 10.5 percent from 9.5 percent by 2018 and its contribution to total employment was expected to grow to about 9.2 percent from 8.4 per cent by 2018 for every 10.8 jobs.

The tourism sectors potential of promoting growth, generating revenue, and creating jobs, for the government was highlighted by Lea (1988) and Sinclair (1998) in their pioneering studies. Actually, the tourismled progress hypothesis proposes that "international tourism is considered as a potential strategic factor for economic growth". An alternative system of export referred to as Tourist spending, is believed to add value to the balance of payments by earnings from foreign exchange as well as proceeds from tourism expansion. This can represent a substantial income source for a country's economy (Balaguer and Cantavella-Jordá 2002). Foreign exchange incomes from tourism can afterward be utilize in the importation of capital goods so as to produce new goods and services, hence, leading to growth in the economic (McKinnon 1964).

Other economic profits derived from tourism actions include employments (it tends to be labor-intensive), tax revenues, and additional income sources (Durbarry 2002). Theoretical analysis has a tendency to posit that expansion of tourism need to have an affirmative contribution to growth in the economy (Balaguer and Cantavella-Jordá 2002; Dritsakis 2004). Recently this concept has attracted significant interest and there exist a lot of empirical papers that confirm the contribution of the tourism industry to a nation's economic growth and development (see Balaguer and Cantavella-Jordá 2002; Dritsakis 2004; Gunduz and Hatemi-J 2005; Kim, Chen, and Jan 2006; Noriko and Motosugu 2007). Equally, Soukiazis and Proença (2005) scrutinized the effect of 
tourism on the local level, Shan and Wilson (2001) studied the causation between trade and tourism. However, it's important to note that few authors found it difficult to establish any optimistic link between economic growth and tourism (see Chen and Devereux 1999; Lee and Chang 2008; Oh 2005).

Regardless of the belief about economic development influenced by tourism, just few studies have rigorously examined a causal relationship between economic growth and tourism. Moreover, many studies have focused on samples of developed nations and despite the growing importance of tourism for economies in Africa, yet even smaller unexpectedly, no studies is yet to meticulously assess the relationship. We are yet to encounter any research evaluating the role tourism plays on the performance of the economy with exclusive focus on rigorous panel and cross-sectional data analysis targeted at developing nations, particularly for cases in Africa. Furthermore, majority of related studies failed to put into consideration the endogeneity concerns and indirect benefits gotten from tourism.

Presently tourism is gaining status as a common phenomenon within Africa particularly, in the Western Africa region due to the endowment of exceptional tourism resource in the region. Christie and Crompton (2001) define Africa's tourism potential as "exceptional", spotting that "Africa has a lot to offer that can no longer be found elsewhere. Africa holds sympathy and certain romanticism as the continent of the explorers and as a place for adventurers. There are unique places, some of the greatest views in the world and natural attractions that few other regions can match. This is true not only for its natural resources, but also for its culture, traditions, and customs" (cited in Naudé and Saayman, 2004).

Despite the earlier stated benefits, some environmental, cultural and social negative impacts affect the sector. However, few individuals believe that the problem is not tourism, but poor planning and ineffectual management of tourism. When managed effectively and efficiently, the tourism sector can definitely be quite less disparaging than non-tourism industries yet, without reduced earning (Kamra and Chand, 2006). This implies that, efficiently and effectively implemented tourism can contribute potentially to local or national economies especially in developing nations including western Africa.

In recent years, with respect to the contributions of tourism to economic (GDP) development, it is important to record that west African region has been recording tremendous upsurge in the tourism and travel GDP, with an average of 62 per cent growth since 2009 in real terms (even though to a minor degree as it is applicable to direct industry GDP). In comparison to the average upsurge of about 31 per cent for the global real term.

On the overall, this industry averaged about 7.2 per cent annual growth rate over the past 10 years (comparatively similar to the rest global shares). An analysis to illustrate the tourism contributions to economic growth is presented in Figure 2 and 3. It is observed that tourism in GDP has been at constant values (2000 constant US\$ billion) from 2009 for the west African countries.

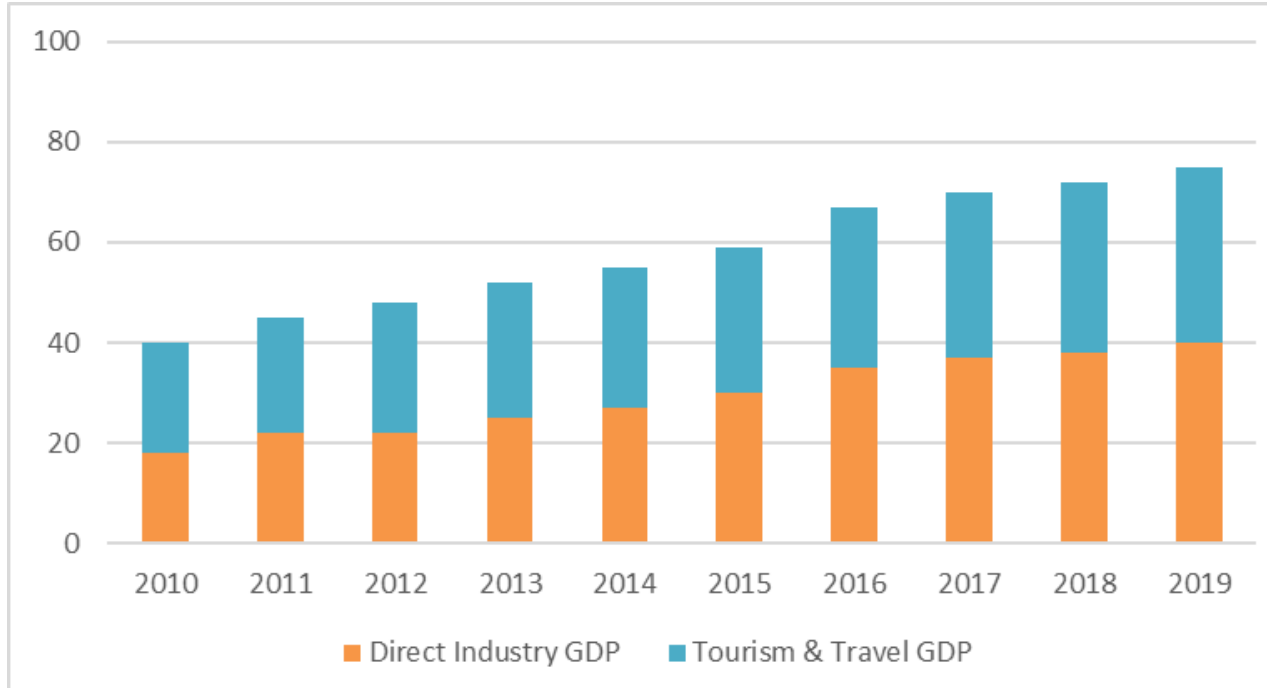

Figure 1: Analysis of GDP performance of Travel and Tourism in West Africa 


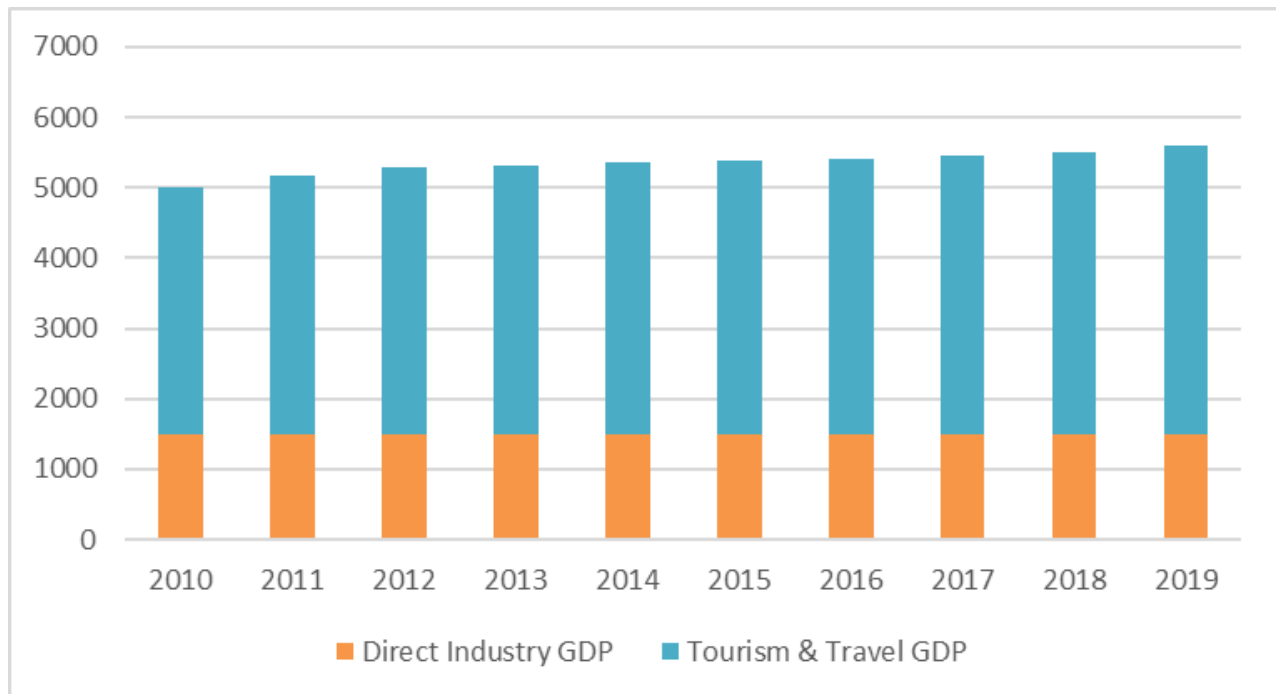

Figure 2: Global GDP of Travel and Tourism (2000 constant US\$ billion)

Considering that economic growth has been identified as one of the most influential instruments for poverty reduction and improving quality of life with developing nations. Recent researches have proved that most economically well-performed countries have strong tourism sector. On the other hand, the expansion of the tourism industry would result in the growth of the economy and expansion through different directions. Thus, the urgent need for poverty assistance in west Africa and the substantial potential economic influence of tourism industry in the regional economy of the west African validates the interest in elucidating the sectors link with economic growth which is the major focus of this research.

1.1.1 Research contributions

This research contributes to existing knowledge in the following ways;

1. To examine the potential determinants of the tourism sector demand including economic growth as measured by GDP per capita in the west African region.

2. To examine the role of tourism on the growth of the west African economy.

3. Using mathematical model to establish the relationship between tourism performance factors and economic growth rate factor.

4. Draw recommendations with respect to the empirical results.

\subsubsection{Research structure}

The remainder of this paper is organized as follows. In section 2, several related previous works are collected, revised and their results compared. The proposed model estimation is presented in section 3. Empirical analysis is performed in section to show the performances of the key study factors. Results, conclusions and recommendations are discussed in section 5.

\section{Literature review}

Presently, the tourism sector frequently gets justified on the grounds of its prospective contribution to development and economic growth. Specifically, it is generally assumed that tourism has the capacity to help eliminate the broadening economic gap between less developed and developed nations as well as ensure steady acceleration of social and economic development, particularly in developing nations (WTO, 1980 cited in Sharpley and Telfer, 2006). Tourism accounts for greater than twice the cash moving to poor countries from rich nations than governments offer in aid. A study of 41 out of the 50 poorest nations of the world shows that, tourism yields over 10\% in exports and over 5\% of GDP (Ashley and Mitchell, 2005). Therefore, it makes the tourism sector very important to Africa on the grounds of the following reasons.

Firstly, although west Africa's contribution to the global tourism figure is little, tourism has a significant contribution to the economy of west Africa. As at 2003 tourism contributed over $11 \%$ of the total exports in Africa- which was $20 \%$ to $30 \%$ of the exports for many nations that exceed the moderate half a million threshold of foreign visitors yearly.

Secondly, the growth of tourism in Western Africa quite fast. As at 1980 , tourism contributed only $2 \%$ in exports of services and goods in west African yet, it currently is at almost six times that level. The West Africa's share in the global market is constantly increasing - such good news about the continent's performance in trade. The sector does not receive the price supports as is the case with agriculture as well as tariff controls giving to those running trade in manufacturing sector.

Thirdly, tourism matters across every part of west Africa. There is a concentration of International arrivals in Nigeria, Cape Verde, Ghana, Togo and Mali, collectively recording nearly three-quarters of the receipts for 
tourism in the continent. But available data in over half of the African countries shows that tourism constitutes above $10 \%$ of the total exports. In nations such as Gambia and Mali, small yearly international figures of 70000 arrivals are significant, and the tourism sector contributes $30.5 \%$ and $10.1 \%$ of the total exports in these nations respectively.

Fourth reason is, the success stories of how some west African countries advanced from the Least Developed Country status as a result of a resilient tourism sector as evidenced by Nigeria and Ghana (Ashley and Mitchell, 2005).

Another brilliance of tourism lies in its spiral effect on nations economic growth and their development. The significance of tourism to the economy of a country can be best measured when we look at the percentage of national income generated by tourism generally referred to as tourism income multiplier (TIM). In any economy experiencing low proportion of leakages, for example, low import levels or low tax rates, TIM will normally be high, while tourism may likely contribute more income than the tourists would have originally spent. (Holloway, 1989).

Economically, factors such as greater income levels, exchange rates and prices are motivating reasons to undertake leisure. Particularly, there is a noteworthy link between motivation and income because higher income tends to diminish some of life uncertainties, thereby releasing people from repetitive concern about need for warmth, shelter, and food. People now seek to advance their lives and living standards not just with the material things but with the experiential too. Travel becomes an essential means of gaining experience and engaging with the novel. Hence, increase in income, likely yields increase in the demand for tourism. (Ryan, 2006).

The price factor is another factor that controls tourism demand. Some theoretical considerations warranted including the price variable as part of the tourism demand-function. Tourism as a consumption good also has differentiation of its price along different contending places of destination. On the grounds of their income constraint, households in a specific nation need to decide first on if they should consume tourist products or choose other category of consumption goods. After a decision is made in support of traveling, the next choice is travel destination taking into cognizance (among other factors) what that the overall journey cost will be, while trying to get the most out of his utility. Nevertheless, tourist demand is not totally dependent on its price level but also depends on the cost of alternative services and goods as well as the domestic market general price level.

Cunha (2001) tries to largely and comprehensively categorize the potential determining factor into: 1) socioeconomic factors which includes income level, demography, relative price difference between the point of origin and the place of destination, urbanization as well as length of the vacation time; 2) technical factors were related to stress-free transport and communications facilities; 3) the psychological and cultural factors deals with the lifestyle and personal preferences of potential travelers; finally, 4) random factors which relate to unexpected events, such as political instability, natural disasters, weather conditions, epidemic diseases, etc.

The relationship between these three features and the growth of tourism appears to be non-linear (EugenioMartín et al., 2004). They are ordinarily required to reach some serious threshold; above which it becomes relatively inefficient to invest. The major glitches that affect tourism in Africa includes poor infrastructure, high airfares, insufficient air transport, deficiency in amenities and accommodation, poor image and perceptions, disease and conflict, poverty (Naudé and Saayman, 2004; Kester, 2003 (cited in Naudé and Saayman; 2004); Christie and Crompton, 2001; Cleverdon, 2002). So long as communication amenities are concerned, the digital gap must be perceived as an important impediment to Africa's tourism development. Merely about $1.5 \mathrm{million}$ out of over 300 million internet users in the world reside in Africa (over $60 \%$ of which are in South Africa) (Cleverdon, 2002 cited in Naudé and Saayman, 2004). The increasingly important role the Internet plays in tourism can be seen through marketing, online booking and information, electronic trade and has considerably increased rivalry between destinations for tourism (Christie and Crompton, 2001). Worthy of note also is the "neighborhood-effects" of security instability in one nation and how it affects the perception about the region in general with "potential tourists regularly unable to differentiate between individual nations" (Kester, 2003 as cited in Naudé and Saayman, 2004). Conversely, tourism appears to be very sensitive to macro-economic stability and decent economic growth (all which has an impact on the price competitiveness of tourism products in a country). Accordingly, tourism remains a significant sector in all Africa's five good performing economies: Mauritius, Morocco, Botswana, South Africa, Tunisia, and (Gauci et al., 2002 cited in Naudé and Saayman, 2004).

The tourism sector has always been regarded as a pivot for economic growth and there are many researches that focus on the area. However, little has been done in developing countries especially in Africa. The limited studies were focused mainly on analyzing determinants of tourist arrivals in the continent, challenges and opportunities, and its economic contribution. In the following paragraphs some of the major empirical works will be presented.

Sequeira and Campos (2005) carried out a research on economic growth and international tourism. They utilized the technique of panel data estimation where they used a five-year data set, an enormous panel of nations and sub-samples of nations that are specialized in tourism. In a bid to test the importance of tourism on nations 
economic growth, they used different variables like tourism specialization (which is quantified as percentage of GDP, population proportion and exports), human capital (proxed by secondary male enrolment), lagged real gross domestic product per capita, consumption-output ratio of government, and the exports plus imports to output ratio (openness). They resolved that tourism; by itself cannot elucidate the greater growth rates noticed in tourism specialized nations, which is conflicting with most previous studies, as they said. However, when they gave a sub-samples of tourism specialist nations, the significance and signs of the estimators of tourism are worth noting (in nations such as Latin America and Africa), in which these countries were expected to have comparative benefit in tourism. This becomes consistent with the argument that support tourism's important role in promoting the growth of poor nations with a fair advantage in tourism. With regards to future research, they suggested the application of A more dynamic panel data as well as an instrumental variable estimator to ascertain the relationship between economic growth and tourism, in order to allow for a greater variation of time-series effects.

Eugenio-Martin et al. (2004) made use of panel data estimation to inspect the relationship between economic growth and tourism within Latin American countries. Using tourists growth rate per capita, public spending on education, gross domestic investment, social variables and general government consumption (political stability and corruption) as the controlled variable for economic growth model while using gross domestic fixed investment, Public fund spending on education per capita, Price calculated to be the ratio between purchasing power parity conversion factor (PPP) and the official exchange rate, school enrollment (tertiary and secondary), trade openness and life expectancy at birth as controlled variable for the tourists arrival-model, they conclusion was that the increasing population of tourists per-capita triggered more economic growth within the low and medium-income nations of Latin America, but did not contribute to any economic growth in wealthier countries. Beyond that, they proposed that if low-income countries would benefit from tourism, then they will need to have sufficient infrastructures, education, as well as development to appeal to tourists. Medium income nations require high GDP per capita and high levels of health services.

Proença and Soukiazis (2005) analyzed tourism demand in Portugal using the econometric method of panel data. Both the supply factors and the demand factors were introduced in the demand function. The variables that were used in explaining the tourism expenditure of the destination country included, the sending country s' real per-capita income, the host country's accommodation size, comparative price between the sending and host countries, and the ratio of public investment in the destination country. Their results exposed per-capita income as the most important determinant of demand and accommodation capacity as the most important determinant of supply that explains movement of tourism in Portugal.

Naudé and Saayman (2004) carried out a research with an aim of understanding what determines the arrivals of tourist in 43 countries of African using a five-years data-set (1996- 2000). The political stability, Number of internet consumers, the per-annum average number of frost days, prevalence of malaria, number of telephone lines used by each employee, air distance, death rate, total quantity of tourist arrivals, GDP per capita, available number of hotel rooms, life expectancy, urbanization rate, adjusted consumer-price index, average hotel room price, were the core variables of the research. They establish that political stability, marketing, tourism infrastructure and information, as well as the development level of the destination are key determinants of traveling to Africa. They also revealed that the classic "developed country determinants" that affect tourism demand, for example, the income level in the origin country, the cost of travel and relative prices are not very significant in elucidating the longing for Africa as a destination for tourism. Bichaka et al. (2007) also studied the effect tourism has on economic development and growth in 42 African nations using panel data. It was found that tourism industry receipts significantly contribute to both the gross domestic product current level and the economic growth of countries in Sub-Saharan African, just as investments does both in physical and humancapital. They concluded that economies in Africa stand a chance of enhancing their economic growth on a shortrun if they can strategically strengthen their tourism sector.

Ashley (2000) evaluated the impact of tourism on rural means of support based on Namibia's Experience. Assessing a collection of livelihood impacts, ascertaining how sector-based policies can be tweaked to enhance effect, and show how the contribution of tourism to livelihoods can be improved by fine-tuning decisions, the study looks at the repercussions of how tourism planners, communities, businesses, other policy-makers and non-governmental organizations (NGOs) work. Based on Namibia's experience he concluded that the 'jobs and cash' effect of tourism development is an over-simplification. Native people have multifarious livelihood strategies, and diverse people have dissimilar livelihood priorities.

Spenceley and Seif (2003) piloted a research that focused on strategies, costs and impacts of pro-poor tourism methods in South Africa. This work describes plans created by five private-sector South African tourism enterprises with the aim of addressing poverty and issues of development within neighboring communities. The non-economic and economic impacts of the tourism sector was the focus of the authors. Furthermore, they assess the effect that pro-poor tourism (PPT) tactics exert on the live condition of the poor citizens in rural settings. The output of the research gives backing to several critical issues like access to market (strength of present economic 
leaders and poor people's location), policy framework (government attitudes and land tenure), commercial sustainability (desirability and product quality, cost benefit and marketing), and implementation issues (capacity gap and skills, collaboration, communication and meeting anticipations). They added that direct employment in the tourism sector is the most important benefits to the poor. Luvanga and Shitundu (2003) critically analyzed the impact tourism has on poverty alleviation within three tourist locations of Tanzania. Conclusively, they found that tourism exudes a high prospective for contributing towards poverty alleviation. Nevertheless, they noted that the success of such poverty alleviation goal is dependent on several policy issues that must be addressed for effective contribution to occur. World Bank (2006) organized a research on behalf of the Ethiopian government entitled "Ethiopia: Towards a Strategy for Pro-Poor Tourism Development." This they did by gathering quantitative data from tourism-centric places (such as Lalibela, Gondar, Bahir-Dar, Axum, ArbaMinch, Harar, and Addis Ababa), the organization attempts to conduct a wide-ranging work within the country. This was done within the ambience of responding to the Ethiopian Governments request to outline a strategy suitable for tourism growth and one that is commensurate with the governments vision for tourism, report had it that the industry was under-performing when compared to the tremendous latent value its cultural heritage should afford it as a tourism industry anchor. According to the research team, this could be best attributed to the weaknesses of Ethiopia's image, her market presence and poor penetration causing an obvious weak demand for her tourism products; a ruthlessly under-valued natural resource and cultural base; uncompetitive support services and suppliers (hotels, activity providers, transporters, handicraft manufacturers and distributors, banks, telecom, restaurants, as well as emergency health services); and lastly the lack of an efficiently communicating and coordinating governance framework to integrate and guide the numerous stakeholders at both sub-country and country levels.

\section{Model selection and estimation}

In this section, two different models are considered: economic growth model and tourists arrival model. The economic growth model tries to explain the economic performance (as estimated by the GDP per capita growth rate) contingent on the number of tourists arrivals in the region assumed as a set of covariates $Y$. The specification of the model is based on Barro (1991) seminal work as it allows us to introduce the concept of conditional convergence. That is, to check if west Africa's lesser developed economies "meet-up" to wealthier west African economies as time goes (the neoclassical economic growth model take up convergence provisional on all economies which have similar stable condition, i.e., very similar technology system, very similar rate of investments and very similar rate of population growth).

On the other hand, the model of tourist arrival makes effort to recognize the contradictory connection, (i.e., to what extent is tourism growth explained by the rate of GDP per capita along with other possible factors of tourism demand).

\subsubsection{Model of Economic Growth}

The gains or loss performance of any rich country is measured by her GDP growth rate. Thus, assuming that $x_{a b}$ represents the income or output per capita of the respective country, then, the growth rate is represented as

$$
x_{a b}-x_{a b-1}=\alpha+\beta x_{a b-1}+\mu_{a b}
$$

where, $\alpha$ is used to represent the stable state, $\mu_{a b}$ denotes the error term, while $-1<\beta<0$ indicates the presence of convergence among different economies $(\beta$-convergence)

In the models of conditional convergence, we utilized a variety of variables as proxies for the diverse stable conditions which consist of, development of the financial system, income distribution, human and physical capital, population, political stability, openness to international trade, fiscal and monetary indicators and technology (Eugenio-Martin et al., 2004). Additionally, number of tourists can be included to control the impact of the increase of tourists on stable condition.

Including those potential variables, we transform (2) and represented it as:

$$
x_{a b}-x_{a b-1}=\alpha+\beta x_{a b-1}+\gamma z \mu_{a b-1}+\mu_{a b}
$$

considering that $z \mu_{a b}$ is the vector of the factors which determine the stable condition per capita income (output). Also, it is established that the specific variables of the unobserved time and country may affect the influence tourism sector has on the economic growth and/or the vise-versa.

Equation (3) augmented by unobserved variables can be specified as follow:

$$
x_{a b}-x_{a b-1}=\alpha+\beta x_{a b-1}+\gamma z \mu_{a b-1}+\alpha_{a}+v_{b}+\mu_{a b}
$$


This equation can be rewritten as:

$$
x_{a b}=\alpha+(1+\beta) x_{a b-1}+\gamma z_{a b-1}+\alpha_{a}+v_{b}+\mu_{i t}
$$

considering $\alpha_{a}$ and $v_{b}$ as correspondingly discrete and sequential impacts which affect the stable condition of individual respective economies. However, the availability of panel data may help to eliminate country and time specific effects by deducting the average value of each variable from the corresponding level variable.

With respect to the econometric model stated above, we project the following equation

$$
\begin{aligned}
L G D P_{p c a b} & =c+(1+\beta) L G D P_{p c_{a b-1}}+\gamma_{1} T O A R_{a b}+\gamma G D I_{a b}+\gamma_{3} P I E_{a b}+\gamma_{4} O G S_{a b} \\
& +\gamma_{5} P S_{a b}+\gamma_{6} Q_{a b}+\gamma_{7} P O P_{a b}+\gamma_{8} D F S_{a b}+\gamma_{9} L B_{a b}+\gamma_{10} T R O P_{a b}+\gamma_{11} T T+\xi_{a b}
\end{aligned}
$$

where $b=1, \ldots, 120(1999-2019), a=1, \ldots, 60$ and $\xi \square N\left(0, \delta_{b}^{2}\right), L G D P_{p c_{a b}}$ represents the logarithm term of GDP per capita, $T O A R_{a b}$ denotes the number of international tourists' arrivals. We represent the gross domestic investment regarding the GDP percentage using $G D I_{a b} . O G S_{a b}$ represents the overall government spending as GDP percentage. $P I E_{a b}$ denotes public investment on education as GDP percentage; $P S_{a b}$ represents the political stability; $Q_{a b}$ is used to demonstrate the quality of governance (with respect to corruption); the factor $L B_{a b}$ denotes the life expectancy at birth. $T R O P_{a b}$ demonstrates the performance of trade openness; $D F S_{a b}$ denotes the development of the financial sector; $T T$ indicates time trend, while $P O P_{a b}$ represents the population.

\subsubsection{Model of Tourists Arrivals}

Following the establishment of the economic growth model, there is need to also develop a model for tourists' arrivals. Estimation of international tourists' arrivals has been an issue that different economic researchers need to pay more attention. In this framework, most of the litterateurs measured the destination cost coupled with tourist's income as the utmost applicable variables in determining tourist's arrivals. However, tourists' choice of destination depends on some other factors too. Hence, the tourists' arrival is modeled in view of four core destination features including: price, regarding consumer price index and exchange rate; infrastructures and investment, which comprises features such as home utilities, hospitals or roads; safety, which includes variables such as income per capita or political stability and education. In line with these, the estimated equation is thus expressed as;

$$
\begin{aligned}
I T p c_{a b} & =c+\gamma_{1} G D P p c_{a b}+\gamma_{2} P_{a b}+\gamma_{3} P S_{a b}+\gamma_{4} d_{1}+\gamma_{5} L_{S S E_{a b}}+\gamma_{6} L_{T S E_{a b}}+\gamma_{7} T R O P_{a b} \\
& +\gamma_{8} D F S_{a b}+\gamma_{9} T T_{b}+\gamma_{10} P I E+\gamma_{11} G D I_{a b}+\gamma_{12} P_{a b}+\xi_{a b}
\end{aligned}
$$

where $b=1, \ldots, 120(1999-2019), a=1, \ldots, 60$. ITpc $c_{a b}$ denote GDP per capita of international tourism arrival. $G D I p c_{a b}$ represents gross domestic investment with respect to the GDP percentage; $G D P p c_{a b}$ illustrates the gross domestic product per capita; $P_{a b}$ represents the price for tourism; $P I E_{a b}$ denotes public investment on education with respect to GDP percentage; ${ }^{L S S E} E_{a b}$ denotes the log of gross admission for secondary school; ${ }^{T R O P} P_{a b}$ demonstrates the performance of trade openness; $P S_{a b}$ represents the political stability; $D F S_{a b}$ denotes the development of the financial sector; ${ }^{d_{1}}$ is used to denote dummy variable utilized to realize country specific variances. In this study, all countries are measured with respect to their individual gross national product (GNP) per capita of the world development indicators (WDI) organization measures where economies below US\$ 912 GNP per capita are classified as lower income economies, while economies that has GNP per capita between $(912$ - 4350) and $(4350$ - 15250) US\$ are classified as lower middle and upper middle income; $T T$ indicates time trend, while $P O P_{a b}$ represents the population.

\subsection{The Panel Data Estimation Approach}

The panel data approach has been employed by many of the recent literatures in macroeconomics. Also, the 
models of panel regression are dependent on panel data approach, which contains repeated observations on identical individual or cross-sectional units over numerous periods of time.

The dataset of panel data technique has several advantages over a single cross-section or time series dataset. First, it can regulate heterogeneity among individual units (in this case, countries). Second, the panel data provide enhanced enlightening data, additional variability, a smaller amount of co-linearity between variables, supplementary degrees of freedom (DoF) and additional productivity by merging the observations of time series of cross-section. Third, by using panel data, economists are permitted to analyze subtleties of modification, and to stipulate and evaluate further difficult and accurate models than a single cross-section or a single time series can perform (Verbeek, 2000; Gujarati, 2004; Baltagi, 1995).

For countries like in west Africa and entire Africa at large that suffered from data shortage, pooling data from different countries provide more variability and enables to classify and estimate the impacts which are not merely obvious in untainted cross section and untainted time series data.

\subsubsection{Generalized Method of Moments (GMM)}

Aside all the gains of the panel data approach, another of its major prospect is capability of the technique to model discrete subtleties. Consider a dynamic model which contain exogenous variables coupled with a lagged dependent variable as presented in (6) below

$$
x_{a b}=y_{a b} \beta+\gamma x_{a b-1}+\alpha_{a}+\xi_{a b}
$$

In a dynamic model $x_{a b-1}$ is based on $\alpha_{a}$ (individual heterogeneity), notwithstanding how $\alpha_{a}$ is treated. Hence, the conventional least squares approaches failed to result in a constant estimate for the fixed effects parameters and the models of random affects. In addition, in those models, the terms of disorder are correlated in sequence, which cause the variables of lagged endogenous to be linked with the terms of disorder (Verbeek, 2000). This is a common problem in estimating growth regressions. This implies that a variable that ought to be contained within in the regression analysis of a conditional convergence, the preliminary level of productivity, is disregarded, hence the analysis of the least squares parameter evaluations will be unfair as a result of the correlation of the disregarded variable with one of the regressors, preliminary income level (Bun and Windmeijer, 2007).

Choosing the right apparatuses of orthogonal circumstances, makes it easy to work out estimators of instrumental variables and their several generalizations for all kinds of model, for example, models that have more than a lag in its dependent variable or the possible correlations that exist between specific effects and exogenous variables.

In the analysis of economic growth, its discovered that the generalized method of moments (GMM) which is an estimation method possess important advantages above simple cross-section regressions as well as other estimation methods used for vibrant panel data-models. First, estimates would not be biased by any excluded variables that are persistent over time (fixed effects or unobserved country-specific). This means that, in regressions of conditional convergence, it avoids the difficulty that is instigated by omitting initial efficiency. Secondly, using instrumental variables permits consistent estimation of parameters in models which involve endogenous variables of right-hand-side. Additionally, using instruments potentially approves consistent estimation in the regardless of error in measurement (Eugenio-Martin et al. 2004; Greene, 2003; Trognon and Seretre, 1996).

In analyzing first-differenced GMM, there is an estimation of the systems of equations both in levels and first differences, when the apparatuses used for the level equations happen to be lagged first-differences of the series. Nevertheless, there is a serious bias in the first-differenced GMM estimators used for empirical growth models. The first-differenced GMM estimator usually behaves poorly whenever the time-series are reported to be persistent and there is a small number of observations for the time series. This happens when the lagged levels of the variables for subsequent first-differences are found to be only weak instruments. If it is such that the instruments are weakly predict the endogenous changes, then, weak instrumental variables will give rise to big predictable sample biases (this happens when instrumental variables are correlated in a poor manner with explanatory variable, nonetheless, such instruments are assumed to be weak. Biased and inconsistent regression estimates are gotten from weak instruments.). That means, the estimator is likely to have very meagre finite sample properties when precision and bias are being considered (Ibid). Bond et al. 2001 proposes two possible solutions aimed at solving the econometric problems above;

a) Strengthening the instrument-set utilized in solving the equations in first-differences through introducing other variables that are not ordinarily added part of the model.

b) To make use of the system GMM estimator introduced by Arellano and Bover (1995).

However, consolidating the instrument-set with external instruments is generally a tough job; Hence, the system GMM estimator is be preferred.

The residual-based t-test of GMM that is relevant to dynamic panel-data models that possess serially correlated 
errors, consist of two interesting facts:

a) The t-test is contingent only on the regularity and not efficiency of the first-step estimation.

b) And the t-test applies to both types of serial correlation (i.e., MA (1) or AR (1)).

If the null-hypothesis becomes statistically confirmed (which means, not rejected), it infers that there is no autocorrelation of the disturbances.

In this study, the proposed GMM estimator utilizes two groups of moment limitations,

$\operatorname{Lim~1:~} E\left(x_{a, b-e} \Delta \xi_{a b}\right)=0$ for $b=3 \ldots B$ and $e \geq 2$

Lim 2: $E\left(x_{a b} \Delta x_{a, b-1}\right)=0$ for $a=1 \ldots M$ and $b=3,4 \ldots B$

The research of Blundell and Bond (1998) also considered an extra hypothesis that $E\left(\alpha_{a} \Delta x_{a 2}\right)=0$ for $a=1 \ldots M$

considering $x_{a}$ as the dependent variable levels; $\alpha_{a}$ is the country-precise impacts that were not observed and $\xi_{a}$ is the error term.

Hence, according to Bond et al. (2001), even though the dependent variable levels $\left(x_{a b}\right)$ are certainly connected with the discrete precise impacts $\left(\alpha_{a}\right)$ the first variances $\left(\Delta x_{a b}\right)$ are not associated with the discrete precise impacts, permitting the use of lagged first variances of the series as tools for calculations in the levels.

3.2.2 Pooled OLS Estimator (POLS)

In the second model a pooled OLS estimator (POLS) is applied. The pooled investigation merges the time series for different cross-sections. Hence, the characteristics of the pooled data is based on recurrent observations on static units. Estimating this kind of model provides answers to several issues that are related to the conventional approaches of the proportional study (i.e., the analysis based on cross-section and time series) as discussed in the earlier section (Podestà, 2000; Gujarati, 2004). However, pooled time series cross-section (TSCS) approaches frequently disrupt the conventional ordinary least squares (OLS) expectations concerning the error development. Therefore, for the regression errors emanating from the OLS to be best it is essential that all the errors assume very similar discrepancy (homoscedasticity) couple with that all of the existing errors are not dependent (independent) of one another.

Errors have a tendency not to be independent from one period to another and errors have a tendency to be heteroscedastic, in a way that they may have contradictory differences across varieties or sub sets of countries. Thus, pooled OLS estimator (POLS) is appropriate where there is contemporaneous exogeneity, no perfect colinearity, homoskedasticity and no serial correlation. To handle the problems of heteroscedasticity and autocorrelation (problems that plague cross-sectional and time series data) the Newey-West (in large samples Newey-West procedure is valid which correct OLS average errors not only in autocorrelation circumstances but likewise in scenarios of heteroscedasticity) method of correcting the OLS average errors are employed (his modified average errors are identified as heteroscedasticity- and autocorrelation-consistent (HAC) average errors or merely as Newey-West average errors.).

\section{Data Analysis and Results}

Data employed in this study is obtained from diverse sources such as from world development indicators, world tourism organizations, Africa development indicators, and the worldwide governance indicators. We collected several macroeconomic variables like GDP per capita, general government consumption and trade openness from the world development indicators (WDI, World Bank, 2018). All except GDP per capita (expressed in 2000 US\$ constant prices) are expressed as percentages. Life expectancy and price variables are also extracted from the same source. For education variables (rate of secondary school gross admission, rate of tertiary gross admission and public educational investments), the World Bank group education statistics (EDSTATS) data query 2018 has been utilized. Gross domestic investment is obtained from the Africa development indicators produced by the World Bank version 2019. The social variables (political stability and corruption) on the other hand are extracted from the worldwide governance indicators (WGI, 2019). Finally, the tourist arrival data is gathered from the world tourism organization (WTO). Owing to data availability, a sample of 8 west African countries are selected. The selected 8 countries represent the higher income earning countries. The series runs from 1999 to 2019 (Tourism data is available only since 1999). Hence, a panel of 320 observations is compiled. To investigate the correlation between economic growth and tourism in west Africa, the study utilizes different social and macro-economic variables which are already analyzed in the previous sections. The gross domestic product (GDP) is the most used macro-economic indicator for measuring output and it is estimated in terms of 
per capita and logarithm. GDP refers to the total of the gross rate summed up by all resident manufacturers in the economy coupled with any taxes of all products and subtract any subventions not comprised in the products value. It is estimated without considering any deductions for devaluation. Dividing the GDP by the midyear population we realized the GDP per capita (GDPpc).

Also, the GDI represents the gross domestic investment as percentage of GDP. This investment includes expenditures on additions to the economies fixed assets coupled with net fluctuations in the level of inventories. Some of the features of the fixed assets are land developments (drains, ditches, fences, etc.); purchase of equipment, machinery and plant purchases; and road and railway construction, and several other constructions such as schools, hospitals, offices, private housing residences, and industrial and commercial edifices. Inventories are stocks of commodities held by companies to attain momentary or unpredicted instabilities in manufacturing or sales, including "work in progress." The rest of the utilized variables are explained in the model.

\subsection{Descriptive analysis}

We first evaluated the performance of both international and domestic tourism arrival in the study regions. The results of these evaluations are presented in Figures 3 ( $a$ and $b$ ), respectively. Figure 3a shows the percentage mean performance of International Tourism arrivals (ITA) during the period of study.
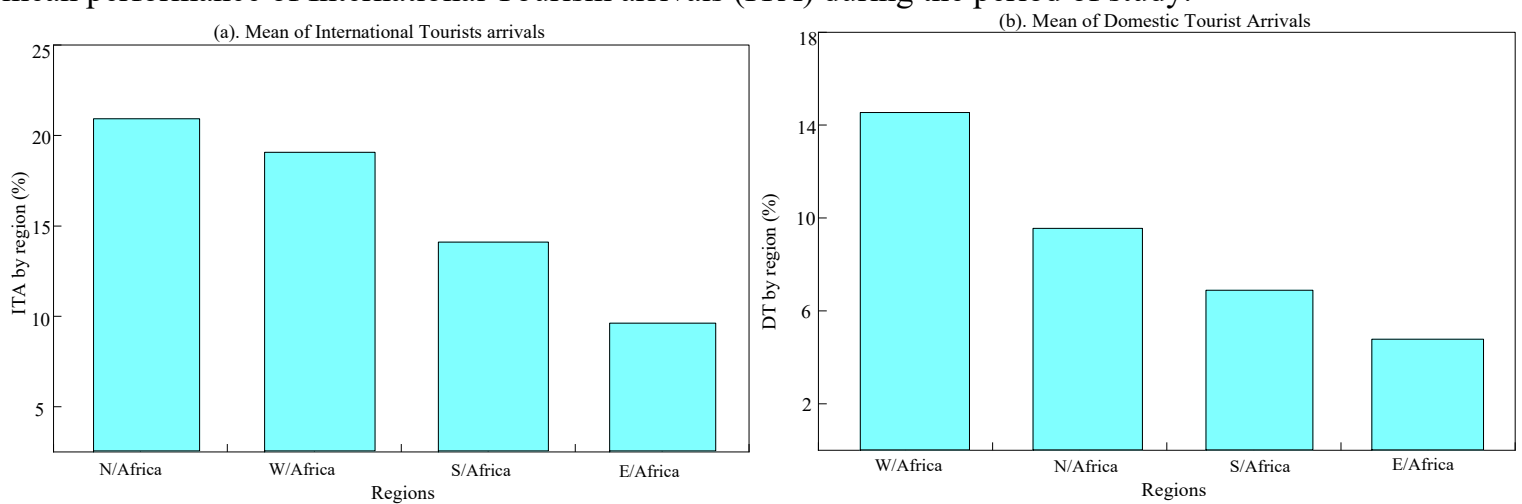

Figure 3: Mean of International and Domestic Tourists arrival by region (\%)

It is observed that the North African (N/Africa) region outperformed the rest of the regions at about 21.85 per cent growth rate of tourists' arrivals. However, the west African region about 18 per cent mean performance of international tourist's arrivals. On the other hand, the east Africa under-performed the rest regions with a lowest score of 7.6 per cent. In Figure 3b, the percentage mean performance of Domestic Tourism (DT) during the period of study is presented. The results show that the west African region also outperformed the rest of the regions at about 15.2 per cent growth rate of tourists' domestic visitations. On the other hand, the east Africa under-performed the rest regions with a lowest score of 5.6 per cent.
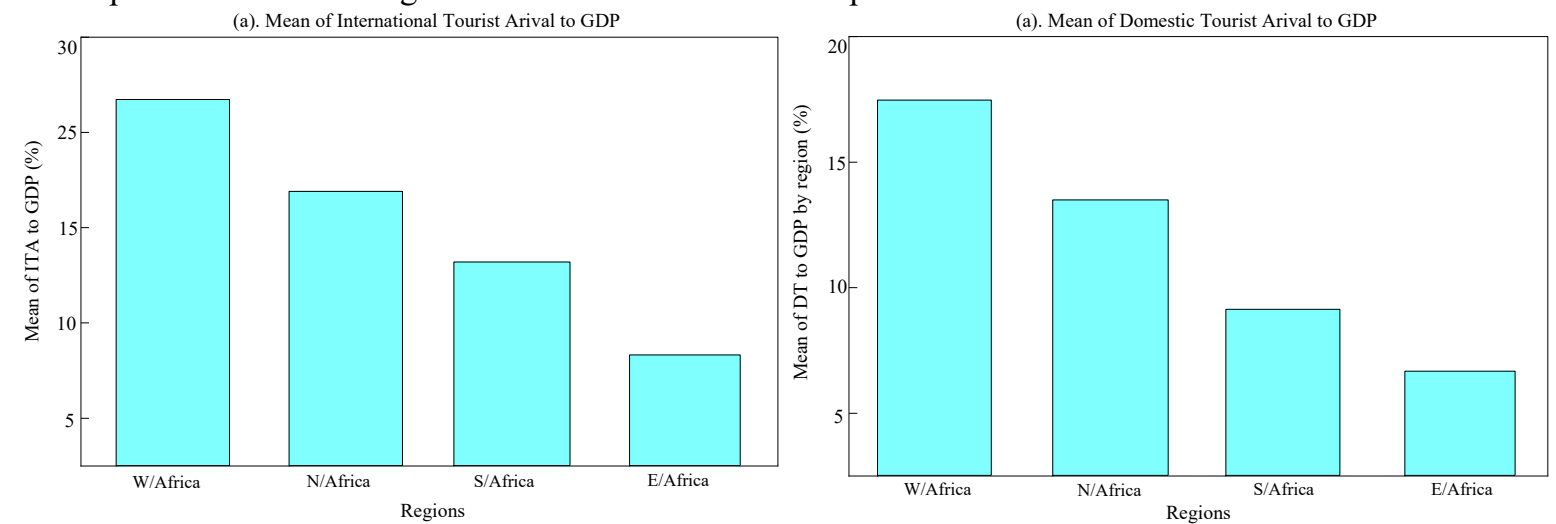

Figure 4: Mean of International and Domestic Tourists arrival to GDP by region (\%)

\subsection{Descriptive Analysis of West African Region}

Following the results established above, the study further narrows down to its case study (west Africa). In this subsection, the focus is to descriptively analyze the performance of tourism and economic growth in the west African region. The west African region is made up of 15 independent countries. However, not all the countries have embraced tourism as a viable source revenue. Also, not all the countries are performing well economically. And most of the countries do not have reasonable data on tourism performance. Therefore, this research selects 
eight best performing countries.

Table 1: Results of summarized statistics for GDP per capita

\begin{tabular}{lrrrr}
\hline GDPpc & Mean & Max & Min & SD \\
\hline Sample & 1012.4 & 12056.5 & 151.2 & 110.8 \\
Nigeria & 7806.5 & 12056.5 & 9312.3 & 821.2 \\
Ghana & 5291.2 & 9389.2 & 4691.4 & 390.1 \\
Burkina Faso & 4522.7 & 9221.8 & 4901.9 & 431.9 \\
Cape Verde & 3361.9 & 7578.9 & 3910.2 & 411.8 \\
Cote D'ivore & 592.2 & 6521.2 & 120.3 & 15.8 \\
Gambia & 423.1 & 3989.3 & 109.9 & 11.6 \\
Liberia & 330.5 & 1899.2 & 101.2 & 9.9 \\
Sierra Leone & 200.9 & 1226.1 & 89.1 & 4.4 \\
\hline \hline
\end{tabular}

The mean GDP per capita of the selected countries is US\$ 1,012 US\$ billion. However, the per capita GDP of the region exhibit strong heterogeneity among the selected countries (see Table 1). This is confirmed by the large standard deviation and significant growth rate difference among the countries sampled. Countries like Nigeria, Ghana, Burkina Faso and Cape Verde are comparatively the three top countries with mean per capita GDP of 7806.5, 5291.2, 4522.7 and 3361.9 USD individually. On the other hand, Cote D'ivore, Gambia, Liberia and Sierra Leone, have the lowest GDP per capita of 592.2, 423.1, 330.5and 200.9 US\$ respectively. The growth rate of countries like Nigeria, Ghana, Burkina Faso and Cape Verde are positive at 7.5, 6.1, 5.5 and 4.2 per cent respectively. On the other side, Cote D'ivore, Gambia, Liberia and Sierra Leone recorded negative growth rate at $-1.2,-1.9,-2.2$ and -4.1 percent respectively.

Table 2: Result of statistical summary of the number of Tourist arrival

\begin{tabular}{lrrrr}
\hline TOAR & Mean & Max & Min & SD \\
\hline Sample & 1332990 & 12329211 & 6000 & 2902659 \\
Nigeria & 512990.8 & 11368922 & 1832566 & 833316.5 \\
Cape Verde & 321809 & 10576901 & 1209899 & 751900.5 \\
Ghana & 202121 & 8002892 & 1109387 & 420911.8 \\
Burkina Faso & 98922 & 6918003 & 900322 & 401823.4 \\
Gambia & 56300 & 6290788 & 830213 & 398102.7 \\
Liberia & 30617 & 5001892 & 690234 & 281092.8 \\
Sierra Leone & 20113 & 4820983 & 602712 & 219028.9 \\
Cote D'ivore & 11900 & 3289102 & 591093 & 163290.2 \\
\hline \hline
\end{tabular}

However, the mean growth of the region is 1.6 per cent. The number of international tourists' arrivals is also illustrated in the cross-country. The region's average tourist arrival is 1,332,990. However, Nigeria, Cape Verde, Ghana and Burkina Faso attract 512,990.8, 321,809, 202,121, and 98,922 tourists' arrivals on average. On the other hand, countries like Gambia, Liberia, and Sierra Leone and Cote D'ivore are limited to 56,300, $30,617,20,113$, and 11,900 respectively. This heterogeneity is clearly indicated by the uneven tourists flow growth rate among the countries of analysis. Even though the region's mean growth rate is 12.5 per cent, some countries scored extreme figures. Ghana, Nigeria, Cape Verde and Burkina Faso have recorded a positive growth rate of 35.6, 23.1, 18.2 and 12.5 per cent respectively. Alternatively, countries like Gambia, Liberia, and Sierra Leone and Cote D'ivore perform a negative growth rate of $-1.6,-2.8,-3.9$ and -4.1 percent respectively.

The dataset showed that there is a high correlation between GDP per capita and tourists' per-capita $(75 \%)$. Although a multivariate analysis is required, this high correlation coefficient between per capita GDP and per capita tourists` arrival implies that economic growth is important for good tourism performance and tourism contributes for economic growth of a country.

\subsection{Empirical Results Discussion}

In this section, results from the two models are presented and discussed.

4.3.1 Economic growth model

Using the Stata 10 statistical software we analyzed and presented the econometric results of the economic growth model in Table 3 . The combined significance of the regressors is significantly maintained by the Wald test (0.0000 P-value). Similarly, the Sargan test (Prob $>$ chi20.1086) for over-identifying restrictions supports the model. In testing autocorrelation, we refuse to accept the null hypothesis which states that there is no autocorrelation in the first order. This is due to the fact that the first variance of white noise is unavoidably autocorrelated. While the null hypothesis is statistically established in the second order test (that is to say, it was not rejected), which implies the fact that the disturbance terms are not auto-correlated.

A significant and positive link is observed to exist between tourist arrival and economic growth indicating the contribution of tourism for economic growth in the west African countries. The result supports the hypothesis 
which states that the contributions of tourism to economic growth is significant and positive in the west African countries. The econometric results also showed that political stability and life expectancy have a significant and positive effect on the economic growth of those countries.

The coefficient of the population variable strongly supports the view of pessimists (Pessimists believe that high population growth has an adverse impact on countries economic growth.). That is high population growth is a burden for economic growth. This view can have acceptance in developing countries like Africa with massive unemployment and unproductive labor. The time trend (included to capture implicit factors such as technological advancement or productivity changes in general) has a positive effect on future growth.

Healthy and strong financial sector is profound for economic growth of a country. However, the sign and significance of the financial sector development indicator variable is surprising. It has a significant and negative impact on economic growth performance. Corruption has a positive sign although it is not statistically significant. Hence, the unexpected sign and significance of the variable in this analysis may be due to the measurement difficulty of corruption that hinders its impact on the economy. This is well explained by Kaufmann (2008). He said, "Africa as a continent is hopelessly corrupt," as well as fallacies on its causes and consequences, were perpetuated. The absence of empirical data on corruption hidden its enormous costs and also gave corrupt politicians "cover", (World Bank, 1999).

Trade openness, gross domestic investment, general government consumption and public spending on education are turned out to be insignificant. The strongly positive and less than one coefficient of the per capita GDP implies the existence of conditional convergence among African countries (The coefficient of the per capita GDP is specified as $(1+\beta))$. In the analysis, the Chi2 stat is applicable for the first two tests.

Table 3: Results of the estimation analysis for Economic growth

\begin{tabular}{llll}
\hline LGDPpc & Coef. & Std. Err. & Z-value \\
LGDPpc & & & \\
\hline L1. & 0.9210025 & 0.0521988 & 21.85 \\
TOAR & $2.52 \mathrm{e}-05$ & $1.38 \mathrm{e}-05$ & $\mathbf{2 . 2 1} * * *$ \\
dscore & 0.0055266 & 0.0025751 & $\mathbf{2 . 0 1} * *$ \\
fscore & 0.0006845 & 0.0020333 & 0.14 \\
POP & $-3.13 \mathrm{e}-08$ & $1.70 \mathrm{e}-08$ & $\mathbf{- 1 . 2 2 * *}$ \\
GDI & -0.0012175 & 0.0000274 & -1.16 \\
DFS & -0.0018181 & 0.000426 & $\mathbf{- 2 . 4 5 * * *}$ \\
PIE & 0.0058471 & 0.0060335 & 0.86 \\
LEB & 0.0081501 & 0.0010461 & $\mathbf{3 . 1 0} * *$ \\
Period & 0.0064048 & 0.0014332 & $\mathbf{1 . 8 4 * * *}$ \\
OGS & $-1.87 \mathrm{e}-07$ & $1.08 \mathrm{e}-07$ & -1.71 \\
TROP & $-6.28 \mathrm{e}-05$ & $5.08 \mathrm{e}-5$ & -1.10 \\
Constant & -12.31366 & 4.028062 & -1.72 \\
\hline Test & Chi2-stat/z-value & P-value & \\
Sargan & 43.61765 & 0.1165 & \\
Wald & 6107.33 & 0.0000 & \\
AR $(1)$ & 1.18 & 0.011 & \\
AR $(2)$ & 0.72 & 0.315 & \\
\hline
\end{tabular}

The * ** and *** show all variables statistical significance at 10, 5 and $1 \%$ level of significance individually. 4.3.2 Tourist arrival model

The F-test, which measures the joint significance of the independent variables, is highly significant $(0.0000 \mathrm{P}$ value) implying good performance of the specified model. GDPpc is positive and highly significant which supports the second hypothesis of the study that economic growth is relevant for the development of the tourism sector. Political stability is undoubtedly basic requirement for a successful tourism industry. Many African countries have been affected by political instability, wars, and ethnic violence, which disrupt their tourism industry. This can be evidenced from Kenya's 2008 election, which rapidly reduced the attraction of tourists within short period of time due to the problem of safety and security created. The positive and strongly significant coefficient of the variable in this study confirms this fact.

The significant and positive coefficient of the tourism openness variable in this analysis indicates the role of the variable in boosting Africa's tourism performance. The reason is that, countries restrictive policies are counterproductive to tourism. Hence, when they open their doors for tourists and have visa-free entry program, definitely tourist arrival boosted. Similarly, Air Port Liberalization (open sky agreement among countries) has a great role in attracting more tourists.

It is reasonable to expect strong positive effect of human capita on tourism per capita. Investments on human capital have a significant impact on productivity. In this analysis, the secondary and tertiary school enrollments that serve as proxy to human capita have positively significant coefficient. However, tertiary 
education is much stronger than the secondary enrollment. The coefficient of the population variable is significantly negative. This implies the adverse effect of population on countries tourism performance.

Table 4: Results of the estimation analysis for Tourists' Arrival

\begin{tabular}{|c|c|c|c|}
\hline ITpc & Coef. & $\begin{array}{l}\text { Newey-West } \\
\text { Std. Err. }\end{array}$ & t-value \\
\hline GDPpc & 0.0000537 & 0.0000033 & $3.38^{* * *}$ \\
\hline $\mathrm{P}$ & $-1.74 \mathrm{e}-06$ & $2.07 \mathrm{e} 06$ & -0.052 \\
\hline dscore & 0.0117562 & 0.0062264 & $2.01 * * *$ \\
\hline $\mathrm{dl}$ & 0.0116640 & 0.0245871 & 0.53 \\
\hline LSSE & 0.0386641 & 0.0128103 & $1.07 * *$ \\
\hline LTSE & 0.0513311 & 0.0100084 & $1.86^{* * *}$ \\
\hline TROP & $6.32 \mathrm{e}-07$ & $1.02 \mathrm{e}-07$ & $6.12 * * *$ \\
\hline PIE & 0.0174354 & 0.0083167 & $2.02 * * *$ \\
\hline POP & $-7.73 e-08$ & $7.21 \mathrm{e}-9$ & $-9.51 * * *$ \\
\hline Period & 0.0002182 & 0.0030311 & 0.07 \\
\hline DFS & 0.0007762 & 0.0005086 & 1.35 \\
\hline GDI & 0.0025063 & 0.0021288 & 1.01 \\
\hline Constant & -1.02468 & 7.122731 & -0.12 \\
\hline Test & $F(12,56)$ & P-value & \\
\hline $\mathrm{F}$ & 28.82 & 0.0000 & \\
\hline
\end{tabular}

The *, ** and $* * *$ show all variables statistical significance at 10,5 and $1 \%$ level of significance individually.

The development of the financial sector development (DSF) and the price variable has the expected sign but not significant. This implies that tourists are much concerned about other factors as political stability, education level, and country's overall progress than quality of services given in the financial sector of destination countries and relative prices of those countries. Similarly, gross domestic investment and public spending on education have the expected sign (positive impact on tourism growth) though gross domestic investment is insignificant.

Country effect dummy (d1) is positive but not significant. This suggests that countries economic development has insignificant spillover effect for further tourism performance. This may justify the impact of west Africa's image on its tourism performance. That is, tourists are influenced by the history of west Africa than by its economic improvement. Similarly, the time trend (included to capture implicit factors such as technological advancement) has insignificant positive effect.

\subsubsection{Formalized Proofs}

At this point, we designed and analyzed some formalized proofs to show the linking relationship that exists between tourism and economic growth in the study area using each dot in the figure as respective country's representation. As seen in Figures 5 to 7, a regression line is snugged to indicate the path of the relationship. The figures illustrate LGDPpc $\mathrm{t}_{-1}$, TROP, GDI, indices PIE, d1 and DFS on the X-axis and the index of Tourism arrival performance (TOAR) on the Y-axis. The analysis show that all the possible factors are positively linked with the index of Tourism arrival.

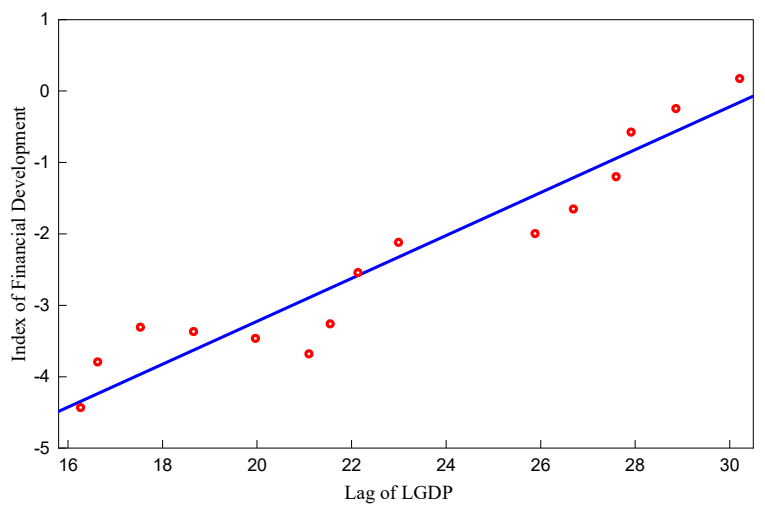

Figure 5: Index of Financial Development vs Lag of LGDP for the study region

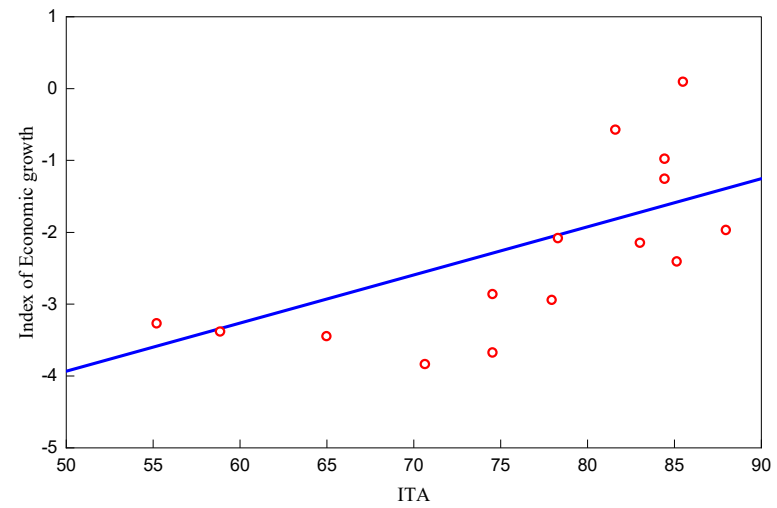

Figure 6: Correlation of the Index of Economic growth vs International Tourist Arrival 


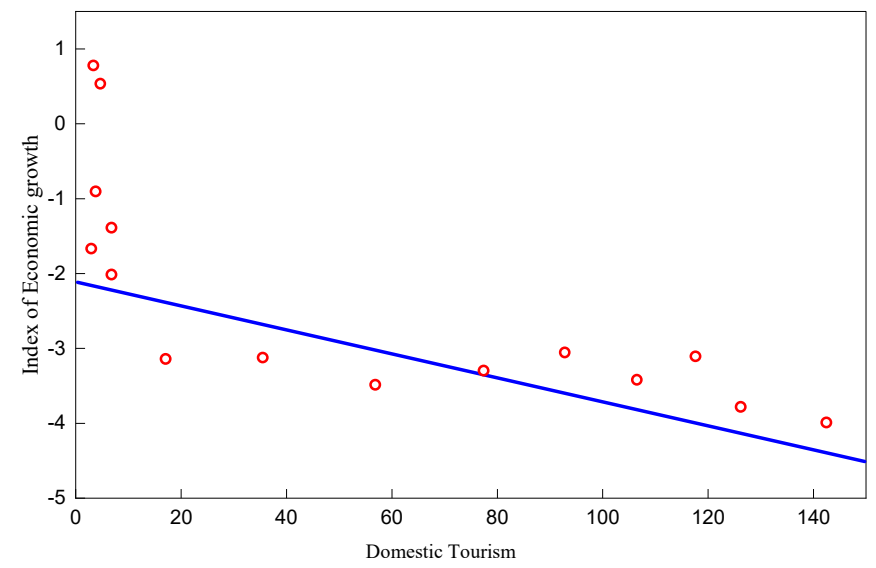

Figure 7: Correlation of the Index of Economic growth

4.3.4. Test of Unit Root

vs Domestic Tourism

To further determine the stationarity of the variables, we employed the Levin, Lin, and Chu (LLC) unit root test approach to establish whether the variables are either stationary or non-stationary (see Levin, Lin, and Chu, 2002). Result of the test show that the null hypothesis which are contained the panels has a unit root. Thus, the result implies that the panels are balanced. Also, results from the LLC test as presented in Table 5 indicate that all the variables are combined of order zero, I (0); that is to say, they are stationary at all levels.

Table 5: Result of the LLC-based Unit Root Test at different Levels

\begin{tabular}{|c|c|c|c|}
\hline Variable & None & Individual Effects & Individual Effects $\&$ trends \\
\hline Economic growth & $-1.77108 * * *$ & 0.88101 & 0.74767 \\
\hline LGDPpc $_{\mathrm{t}-1}$ & 18.6102 & 3.11227 & $-3.77171 * * *$ \\
\hline $\mathrm{LGDPpc}_{\mathrm{t}-1}(\mathrm{c})$ & 4.85301 & 3.01217 & $-3.77173 * * *$ \\
\hline TROP & $-0.42487 *$ & $1.17417 * *$ & -0.30557 \\
\hline TROP (c) & $-5.03777 * * *$ & $-1.17617 * *$ & -0.30557 \\
\hline TOAR & $-6.58325 * * *$ & $-4.32781 * * *$ & $-3.78025 * * *$ \\
\hline TOAR (c) & $-4.02178 * * *$ & $-3.11467 * * *$ & $0.00012 * * *$ \\
\hline GDI & $-9.8702 * * *$ & $-4.32781 * * *$ & $-3.78025 * * *$ \\
\hline PIE & $-13.0584 * * *$ & $-9.86774 * * *$ & $-10.6081 * * *$ \\
\hline DFS & -0.02355 & $-9.86771 * * *$ & $-8.6284 * * *$ \\
\hline d1 & $-1.55711 * *$ & $-5.62284 * * *$ & $-11.5148 * * *$ \\
\hline
\end{tabular}

Source: Author's computation (2021) Note: ***, **, and * denote stationary at 1\%, 5\%, and $10 \%$ levels of significance respectively. (c) defines mean-centered variable

\section{Conclusion and Policy recommendations}

\subsection{Conclusion}

Tourism can serve as source of foreign exchange earnings, income and employment. The purpose of this thesis was to explore the link between the tourism sector and economic growth using panel dataset for the period 1999 - 2019 for six west African countries. The research applied pooled ordinary least squares and a dynamic panel estimated by the systems generalized method of moment's estimator. The following are what the findings show;

1. The findings showed that there is a positive correlation between economic growth and tourism sector.

2. The result is in line with our hypothesis that the tourism sector will have a significant positive contribution to the economic growth of west African countries and economic growth is also, a relevant input for tourism sector development.

3. In addition to economic growth measured by GDP per capita, political instability, tourism openness and human capital are important variables as they contribute to under-utilization of tourism resources.

\subsection{Policy Implications}

Following the results achieved in the cause of the research, the policy implications of the research findings can be stated as follows;

1. The west African countries should create conducive environment (e.g., political stability) and commit their resources to increase the contribution of the tourism sector to national income. Specifically, the west African countries should give the sector the needed attention by committing their resources to improve their human capital, openness to tourism and their economic growth in general whose expenses promise significant contributions to national income, employment opportunities and foreign exchange 
earnings.

2. Promotion of local market along the borders of a region is a big step towards tourism improvements.

3. More precisely, receiving of the positive relation hypothesis and acceptance of tourism-led growth have implications for articulating policies that are based on tourism. With reference to longstanding and continued growth, investment in conventional determinants, investment in tourism and well-planned tourism activities are vital to optimize tourism incomes. Nevertheless, tourism correlated strategies should be judiciously considered with the intention of operating with an organization that is favorable to the tourism industry.

4. Finally, policy makers should be careful in enacting strategies, particularly in considering the share value of investment among tourism and other prolific industries. An extremely endorsed tourism industry can result in a 'tremendous economic growth' because tourism is a very volatile industry which is open to exposure by several outward determinant and factors, leaving a nation in underprivileged economic situations.

\section{References}

Akama, J. (1999). "The Evolution of Tourism in Kenya", Department of Tourism, Moi University, Kenya. allmattersafrican.com, January 22, 2007.

Ariyo, A. (1996). "Quality of Macroeconomic Data on Africa: Nigeria as a case study", The African Economic Research Consortium, Nairobi, Kenya.

Ashe, JW. (2005)." Tourism Investment as a Tool for Development and Poverty Reduction: The Experience in Small Island Developing States (SIDS)".

Ashley, C. (2000). "The Impacts of Tourism on Rural Livelihoods: Namibia's Experience”, Chameleon, Press, London SW18 4SG, Overseas Development Institute.

Ashley, C. and Mitchell, J. (2005). "Can Tourism Accelerate Pro-Poor Growth in Africa?" Overseas Development Institute, ODI.

Baltagi, B. (1995). "Econometric Analysis of Panel data", John Wiley and Sons Ltd.

Barro, R. (1991). "Economic Growth in a Cross Section of Countries", Quarterly Journal of Economics, 106, 2:407-443

Blundell, R. and Bond, S. (1998). "Initial Conditions and Moment Restrictions in Dynamic Panel Data Models", Journal of Econometrics 87, 115-143.

Bond, S., Hoeffle, A. and Temple, J. (2001). "GMM Estimation of Empirical Growth Models”, Working Paper, University of Oxford.

Bowshe, C.G. (2000). “On Testing Over identifying Restrictions in Dynamic Panel Data Models”, Nuffield College, University of Oxford, Oxford, OX1 1NF, United Kingdom.

Bun, M. and Windmeijer, F. (2007). "The Weak Instrument Problem of the System GMM Estimator in Dynamic Panel Data Models", Discussion Paper 07/595, University of Bristol.

Christie, I. and Crompton, D. (2001). "Tourism in Africa", African Region Working Paper Series no. 12, the World Bank, Washington DC.

Christie, T. and Elizabeth, D. (2001)." Tourism in Africa", Africa Working Paper Series, N. 12, World Bank.

David, D. and Brandl, M. (1996)," African convergence clubs: the effects of colonialism and trade", the University of Texas at Austin Graduate school of Business, version: July 1996.

David, R. (2007). "The Concise Encyclopedia of Economics", ed. Liberty Fund. Addis Ababa University School of Graduate Studies Tourism and Economic growth in Africa (2008)

Dieke, P. (2003). "Tourism in Africa's Economic Development”, Policy Implications, The Emirates Academy of Hospitality Management, Dubai, United Arab Emirates.

Eugenio-Martín, J.L., Morales, N.M. and Scarpa, R. (2004). "Tourism and Economic Growth in Latin American Countries: a panel data approach", University of New York environment department.

Fayissa, B. Nsiah, C. and Tadasse, B. (2007). "The Impact of Tourism on Economic Growth and Development in Africa", Department of economics and finance working paper series, August.

Fkru, D. (2007). "Analysis of the Behavior of Private Investment in Response to Fiscal policy Changes in SubSaharan Africa", Addis Ababa University (Unpublished).

Greene, W. (2003). "Econometric Analysis", New York University, Prentice Hall.

Gujarati, D. (2004). "Basic Econometrics", Fourth edition, The McGraw-Hill Companies,

Hall, M. and Jenkins, J. (2004). "A Companion to Tourism", Black well.

Holloway, J. (1989). "The Business of Tourism", 3rd edition, London.

Jung, H. (2005). "Some Developments in Dynamic Panel Data Analysis", Graduate School of Economics, Hitotsubashi University.

Kamra, K. and Chand, M. (2006). "Basics of Tourism, Theory, Operation and Practice", New Delhi.

Kaufmann, D., Kraay, A. and Mastruzzi, M. (2006). "Governance Matters V: Aggregate and Individual 
Governance Indicators for 1996-2005”, the World Bank.

Luvanga, N. and Shitundu, J. (2003). "The Role of Tourism in Poverty Alleviation in Tanzania”, Mkukina Nyota Dar es Salaam, Tanzania.

Muluken, H. (2006). "Ethiopian Tourism: Performance, Contribution and Factors Affecting its Development", Addis Ababa University (Unpublished).

Naudé, W. and Saayman, A. (2004). "The Determinants of Tourist Arrivals in Africa: A panel data regression analysis", North-West University, Potchefstroom Campus, South Africa.

Ndulu, B. (2004). "Economic Growth and the Challenge of Reducing Poverty and under nutrition in Africa", Development Economics Research Department, World Bank, U.S.A.

Organization for Economic collaboration and Development, (2000). "Swiss Tourism Policy - a Synthesis", Directorate for Science, Technology and Industry.

Philips, L. and Alastair, M. (2001). "Tourism Bridges Across Countries”, McGraw-Hill Australia.

Podestà, F. (2000). "Recent Developments in Quantitative Comparative Methodology: the case of Pooled Time Series Cross-Section Analysis", Georgetown University, discussion papers soc 3-02.

Pogreba, D. (2006). "Poverty in Africa", a topic paper prepared for the National Debate Topic Selection Committee of the NFSHA, Helena MT.

Proença, S. and Soukiazis, E. (2005). "Demand for Tourism in Portugal: a Panel Data Approach", Discussion paper $\mathrm{N}^{\circ} 29$, Coimbra.

Roodman, D. (2006). "How to do xtabond2: An introduction to "Difference" and "System" GMM in stata", Center for Global Development, Working paper $N^{\circ} .103$.

Round, J. (2007). "Globalization, Growth, Inequality and Poverty in Africa", world institute for development economics research Paper No. 2007/55.

Ryan, C. (2006). "Recreational Tourism: Demand and Impacts", Vinod Vasishtha, New Delhi.

Sequeira, T. and Campos, C. (2005). "International Tourism and Economic Growth: A Panel Data Approach", Social Science Research Network Electronic Paper Collection.

Sharpley, R. and Telfer, D. (2006). "Tourism and Development", Vinod Vasishtha, New Delhi.

Spenceley, A. and Seif, J. (2003). "Strategies, Impacts and Costs of Pro-Poor Tourism Approaches in South Africa", PPT Working Paper No. 11, South Africa.

The World Bank Group education statistics (2018). [edstats] data query, website

Torjman, S. (2005). "What is Policy?" The Caledon, Institute of Social Policy.

Trognon, A. and Sevestre, P. (1996). "The Econometrics of Panel Data", A Hand Book of the Theory with Applications, 2nd edition, Kluwer Academic Publishers, London.

Verbeek, M. (2000). "A Guide to Modern Econometrics", John Wiley and Sons Ltd, England.

White, H. and Killick, T. (2001). "Poverty in Africa at the New Millennium:" the World Bank Washington, D.C.

World Bank, (1999). "Can Corruption be measured?” Banks World, Vol. 3, No. 6.

World Bank, (2019). “Africa Development Indicators”, Data Base, CD-ROM.

World Bank, (2019). "Ghana: Towards a Strategy for Pro-Poor Tourism Development", Private Sector Development, Report No. -ET.

World Bank, (2018). "World Development Indicators (WDI)", Data Base, CD-ROM.

World Tourism Organization, (2018)." Compendium of Tourism Statistics (1999-2018)", Madrid: WTO.

World Tourism Organization, (2019)." WTO in Africa 1999-2019”, Madrid: WTO.

World Travel and Tourism Organization and International Hotel and Restaurant Association, (1999).

"Tourism and Sustainable Development: The Global Importance of Tourism", Background Paper, New York.

Worldwide Governance Indicators (WGI) 2018, website. 